\title{
Desain Modifikasi Struktur Gedung Hotel Premier Inn Surabaya dengan Menggunakan Beton Prategang dan Sistem Rangka Pemikul Momen Khusus (SRPMK)
}

\author{
Firdauziah Ramadhani, I Gusti Putu Raka, dan Tavio \\ Departemen Teknik Sipil, Fakultas Teknik Sipil dan Perencanaan, Institut Teknologi Sepuluh Nopember (ITS) \\ e-mail: raka@ce.its.ac.id
}

\begin{abstract}
Abstrak-Beton prategang merupakan teknologi beton struktural yang sering digunakan untuk mengakomodir kebutuhan ruang yang lebih luas tanpa adanya gangguan dari kolom. Balok beton prategang mengijinkan perancang untuk mendesain bentang yang lebih panjang dibandingkan dengan balok beton bertulang dengan bentang pendek. Gedung hotel Premier Inn Surabaya ini memiliki 18 lantai, dimana lantai 16 dan lantai atapnya dimodifikasi dengan balok beton prategang. Hal ini berdasarkan kebutuhan ruang yang luas sebagai ballroom tanpa adanya kolom pada lantai 15 dan 16 untuk memikul bentang bebas sepanjang $12,25 \mathrm{~m}$. Sistem struktur yang digunakan adalah Sistem Rangka Pemikul Momen Khusus (SRPMK) dikarenakan Kategori Desain Seismik (KDS) bangunan ini yaitu KDS-D. Pembebanan yang digunakan dalam desain mengacu PPIUG 1983 dan perhitungan gaya gempa dengan metode respon spektrum berdasarkan SNI 1726:2012 dan Peta Hazard Gempa Indonesia 2010. Sedangkan untuk desain struktur beton mengacu pada SNI 2847:2013. Hasil dari desain bangunan ini menunjukkan bahwa telah memenuhi semua persyaratan sehingga mampu untuk menahan beban gravitasi dan beban gempa di wilayah kota Surabaya.
\end{abstract}

Kata Kunci-Beton Prategang, Beton Bertulang, Gempa, Respon Spektrum, Sistem Rangka Pemikul Momen Khusus.

\section{PENDAHULUAN}

B ETON adalah material yang kuat dalam kondisi tekan, tetapi lemah dalam kondisi tarik (kuat tariknya bervariasi dari 8 sampai 14 persen dari kuat tekannya). Karena rendahnya kapasitas tarik tersebut, maka retak lentur terjadi pada taraf pembebanan yang masih rendah [1]. Pada struktur dengan bentang yang panjang, struktur beton bertulang biasa tidak cukup untuk menahan tegangan lentur sehingga terjadi keretakan di daerah yang mempunyai tegangan lentur, geser atau puntir yang tinggi. Keretakan ini memungkinkan masuknya pengaruh korosif yang akan merusak tulangan dan membahayakan struktur, dengan adanya kelemahan yang terjadi pada struktur beton bertulang tersebut, maka timbullah gagasan untuk menggunakan kombinasi bahan beton secara lain, yaitu dengan memberikan prategang pada beton melalui kabel baja (tendon) yang ditarik atau biasa disebut beton prategang.

Beton prategang merupakan teknologi konstruksi beton yang mengkombinasikan dua jenis bahan mutu tinggi yaitu beton dan baja, dengan cara menarik baja tersebut dan menahannya dalam beton sehingga membuat beton dalam keadaan tertekan. Kombinasi dari kedua bahan tersebut menghasilkan perilaku yang lebih baik. Kemampuan beton menahan tarikan diperbaiki dengan memberikan tekanan, sementara kemampuannya menahan tekanan tidak dikurangi. Sehingga beton prategang mempunyai kombinasi yang ideal.

Pada Studi ini, perencanakan struktur gedung Hotel Premier Inn di Jl. Biliton No. 24-26 Surabaya ini semula memiliki ketinggian bangunan 10 lantai. Kemudian dimodifikasi dengan ketinggian bangunan menjadi 17 lantai. Gedung hotel ini juga dimodifikasi menggunakan beton prategang pada lantai 16 dan lantai atap, dimana pada lantai 15 dan 16 terdapat ruangan tanpa adanya kolom ditengah bentang yang akan difungsikan sebagai ballroom.

Hotel Premier Inn Surabaya ini direncanakan menggunakan beban gempa respon spektrum sesuai dengan Standar Perencanaan Ketahanan Gempa untuk Struktur Bangunan Gedung dan Non Gedung (SNI 1726-2012) dan dengan metode Sistem Rangka Pemikul Momen Khusus (SRPMK). Maka pada Studi ini direncanakan menggunakan SRPMK dimana sistem ini didesain untuk daerah zona gempa tinggi dengan pembebanan struktur sesuai peraturan SNI 2847-2013.

\section{METODE STUDI}

Perencanaan struktur gedung tahan gempa di Indonesia sangat penting mengingat sebagian besar wilayahnya berada dalam area cincin api, yang memiliki intensitas gempa rendah hingga tinggi. Salah satu syarat penting struktur tahan gempa adalah daktilitas yang memadai. Sebuah struktur memiliki daktilitas yang baik bila elemen-elemen struktur penyusunnya juga memiliki daktilitas yang baik.

Didalam perencanaan suatu struktur harus selalu diperhatikan hal-hal sebagai berikut : 1). Dari segi kekuatan, struktur tersebut harus dapat diandalkan kekuatannya, 2). Dari segi estetika memenuhi syarat keindahan dan 3). Dari segi finansial struktur tersebut harus ekonomis. Apabila semua persyaratan diatas terpenuhi, maka dapat dikatakan bahwa struktur yang direncanakan memenuhi persyaratan teknis.

Konstruksi dengan beton bertulang merupakan jenis konstruksi yang paling banyak digunakan karena mudah dalam mendapatkan material dan pelaksanaannya. Beton bertulang efektif digunakan pada konstruksi dengan bentang balok yang tidak terlalu panjang. Sedangkan untuk konstruksi balok dengan bentang yang panjang digunakan beton prategang dengan dimensi yang relatif kecil. 
Penggunaan beton bertulang tidak efisien karena ukuran balok menjadi sangat besar sehingga tidak sesuai dengan segi estetika dan arsitektural. Selain itu, beban sendiri dari beton bertulang menjadi dominan dan beban gempa juga akan meningkat. Salah satu solusi yang bisa digunakan yaitu dengan menggunakan sistem beton prategang [2].

\section{A. Konsep Desain Kapasitas}

Konsep desain kapasitas adalah mengatur bagian yang satu lebih kuat dari bagian yang lain, sehingga bentuk keruntuhan dapat ditentukan lebih dahulu. Berikut adalah contoh dua mekanisme keruntuhan yang dapat terjadi pada portal - portal rangka terbuka.
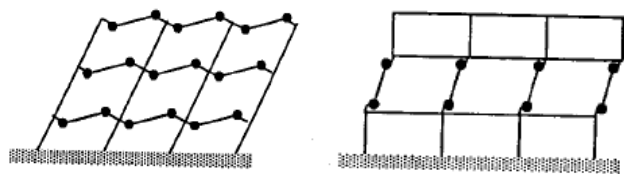

Gambar 1. Macam-macam mekanisme keruntuhan pada portal rangka terbuka.

Pada struktur gedung dengan sistem rangka pemikul momen khusus harus didesain memenuhi syarat "Strong Column Weak Beam", yang artinya ketika menerima pengaruh gempa hanya boleh terjadi sendi plastis di ujungujung balok dan kaki kolom saja.

\section{B. Sistem Rangka Pemikul Momen (SRPM)}

Menurut SNI 1726:2012 pasal 3.53 sistem rangka pemikul momen merupakan sistem struktur yang pada dasarnya memiliki rangka ruang yang berfungsi untuk memikul beban gravitasi secara lengkap. SRPM ini dibagi menjadi tiga jenis, yaitu : Sistem Rangka Pemikul Momen Biasa (SRPMB), Sistem Rangka Pemikul Momen Menengah (SRPMM), dan Sistem Rangka Pemikul Momen Khusus (SRPMK).

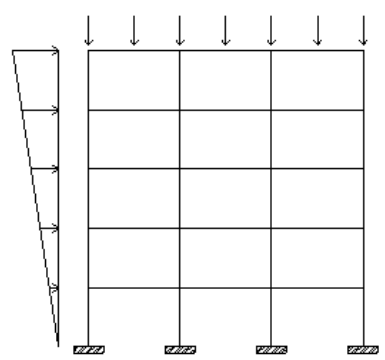

Gambar 2. Sistem Rangka Pemikul Momen.

Berdasarkan SNI 2847:2013, perencanaan pembangunan gedung bertingkat untuk daerah dengan resiko gempa tinggi mengunakan Sistem Rangka Pemikul Momen Khusus (SRPMK). Struktur beton bertulang yang berada pada wilayah gempa dan resiko gempa kuat (kerusakan merupakan resiko utama), maka komponen struktur harus memenuhi syarat perencanaan dan pendetailan dari SNI 2847:2013 pasal 21.5.

\section{Sistem Beton Prategang}

Beton prategang merupakan teknologi konstruksi beton yang mengkombinasikan antara beton berkekuatan tinggi dengan baja mutu tinggi dengan cara aktif. Beton prategang merupakan kombinasi yang ideal dari dua buah bahan modern yang berkekuatan tinggi [3].

1. Beton Prategang metode Pratarik (Pratension)
Sistem pemberian gaya prategang pada beton pratekan dengan menarik baja prategang (tendon) terlebih dahulu sebelum dilakukannya pengecoran. Cara ini sering digunakan di laboratorium atau pabrik beton pracetak (Precast Prestressed Concrete) dimana terdapat lantai penahan tarikan yang tetap atau di lapangan dimana dinding penahan dapat dibuat secara ekonomis.

2. Beton Prategang metode Pascatarik (Post Tension)

Sistem pemberian gaya prategang pada beton yang metodenya dilakukan dengan cara menarik baja prategang (tendon) setelah balok dicor dan mencapai sebagian besar dari kuat betonnya.

\section{KONTROL HASIL ANALISIS STRUKTUR}

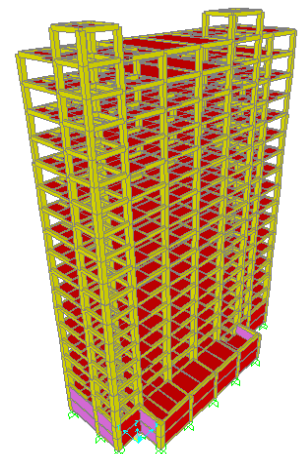

Gambar 3. Pemodelan Struktur dengan Program bantu SAP 2000

\section{A. Kontrol Periode}

Periode struktur fundamental, $T$, dalam arah yang ditinjau harus diperoleh menggunakan properti struktur dan karakteristik deformasi elemen penahan dalam analisis yang teruji. Periode fundamental, $\mathrm{T}$, tidak boleh melebihi hasil koefisien untuk batasan atas pada periode yang dihitung $(\mathrm{Cu})$ dan periode fundamental pendekatan, Ta.

Tabel 1.

Nilai Periode Struktur (T) dari program SAP2000

\begin{tabular}{cccc}
\hline \hline \multicolumn{3}{c}{ TABLE: Modal Participating Mass Ratios } \\
$\begin{array}{c}\text { OutputCase } \\
\text { Text }\end{array}$ & $\begin{array}{c}\text { StepType } \\
\text { Text }\end{array}$ & $\begin{array}{c}\text { StepNum } \\
\text { Unitless }\end{array}$ & $\begin{array}{c}\text { Period } \\
\text { Sec }\end{array}$ \\
\hline MODAL & Mode & 1 & 2.227524 \\
MODAL & Mode & 2 & 1.946547 \\
MODAL & Mode & 3 & 1.879832 \\
MODAL & Mode & 4 & 0.721847 \\
MODAL & Mode & 5 & 0.644067 \\
MODAL & Mode & 6 & 0.620814 \\
MODAL & Mode & 7 & 0.399359 \\
MODAL & Mode & 8 & 0.366201 \\
MODAL & Mode & 9 & 0.347895 \\
MODAL & Mode & 10 & 0.266876 \\
MODAL & Mode & 11 & 0.247087 \\
MODAL & Mode & 12 & 0.192808 \\
MODAL & Mode & 13 & 0.189349 \\
MODAL & Mode & 14 & 0.168518 \\
MODAL & Mode & 15 & 0.144378 \\
MODAL & Mode & 16 & 0.124283 \\
MODAL & Mode & 17 & 0.098111 \\
MODAL & Mode & 18 & 0.077265 \\
MODAL & Mode & 19 & 0.04395 \\
MODAL & Mode & 20 & 0.037408 \\
\hline \hline
\end{tabular}

Pada perhitungan sebelumnya didapatkan perioda batasan atas sebesar $C u \times T \mathrm{a}=2,81$ detik. Dari hasil analisis program SAP2000 didapat $T_{c}=2,228$ detik. Karena $T_{a}<T_{c}$ $<C_{u} \times T_{a}$ maka periode fundamental struktur yang digunakan adalah $\boldsymbol{T}=\mathbf{2 , 2 2 8}$ detik.

B. Kontrol Nilai Akhir Respons Spektrum 
Nilai akhir Vdinamik harus lebih besar sama dengan $85 \%$ Vstatik. Maka persyaratan tersebut dapat dinyatakan sebagai berikut :

$$
\text { Vdinamik } \geq 0,85 \text { Vstatik }
$$

Tabel 2.

Faktor Skala Gempa

\begin{tabular}{|c|c|c|c|c|}
\multicolumn{1}{|c|}{} & \multirow{2}{*}{$F x(k g)$} & $F y(k g)$ & \multicolumn{2}{|c|}{ Faktor Skala } \\
\cline { 1 - 2 } & & & $F x$ & $F y$ \\
\hline V dinamik & 320286.38 & & 1.3 & \\
\cline { 1 - 2 } 0.85 V statik & 398240.893 & & & \multirow{2}{*}{1.3} \\
\hline V dinamik & & 302387.23 & & \\
\cline { 1 - 2 } 0.85 V statik & & 398240.893 & & \\
\hline
\end{tabular}

Tabel 3.

Kontrol Akhir Berdasarkan Faktor Skala Gaya Gempa

\begin{tabular}{|c|c|c|c|c|}
\hline & \multirow{2}{*}{$F x(\mathrm{~kg})$} & \multirow{2}{*}{$F y(\mathrm{~kg})$} & \multicolumn{2}{|c|}{ Kontrol Akhir } \\
\cline { 1 - 1 } & & & $F x$ & $F y$ \\
\hline V dinamik & 436372.52 & & \multirow{2}{*}{ Oke } & \\
\hline 0.85 V statik & 398240.893 & & & \\
\hline V dinamik & & 420343 & & \multirow{2}{*}{ Oke } \\
\cline { 1 - 1 } 0.85 V statik & & 398240.89 & & \\
\hline
\end{tabular}

\section{Kontrol Nilai Partisipasi Massa}

Berdasarkan SNI 1726:2012 Ps. 7.9.1 bahwa analisis harus menyertakan jumlah ragam yang cukup untuk mendapatkan partisipasi massa ragam terkombinasi paling sedikit $90 \%$ dari respon total dari perhitungan respon dinamik.

Tabel 4.

Rasio Partisipasi Massa

\begin{tabular}{cccr}
\multicolumn{4}{c}{ Rasio Partisipasi Massa } \\
\hline \multicolumn{5}{c}{ TABLE: } & Modal Participating Mass Ratios \\
OutputCase & Period & SumUX & SumUY \\
Text & Sec & Unitless & Unitless \\
\hline MODAL & 2.227524 & 0.000007742 & 0.551 \\
MODAL & 1.946547 & 0.462 & 0.551 \\
MODAL & 1.879832 & 0.561 & 0.552 \\
MODAL & 0.721847 & 0.561 & 0.639 \\
MODAL & 0.644067 & 0.63 & 0.639 \\
MODAL & 0.620814 & 0.64 & 0.639 \\
MODAL & 0.399359 & 0.64 & 0.672 \\
MODAL & 0.366201 & 0.67 & 0.672 \\
MODAL & 0.347895 & 0.671 & 0.672 \\
MODAL & 0.266876 & 0.671 & 0.692 \\
MODAL & 0.247087 & 0.689 & 0.692 \\
MODAL & 0.192808 & 0.689 & 0.703 \\
MODAL & 0.189349 & 0.694 & 0.706 \\
MODAL & 0.168518 & 0.703 & 0.706 \\
MODAL & 0.144378 & 0.705 & 0.717 \\
MODAL & 0.124283 & 0.713 & 0.723 \\
MODAL & 0.098111 & 0.725 & 0.732 \\
MODAL & 0.077265 & 0.73 & 0.764 \\
MODAL & 0.04395 & 0.743 & 0.914 \\
MODAL & $\mathbf{0 . 0 3 7 4 0 8}$ & $\mathbf{0 . 9 1 5}$ & $\mathbf{0 . 9 2 4}$ \\
\hline \hline
\end{tabular}

\section{Kontrol Simpangan (Drift)}

Berdasarkan SNI 1726:2012 kontrol drift dan syarat drift harus ditentukan berdasarkan perumusan 34 pada SNI 1726:2012 Pasal 7.8.6 yaitu sebagai berikut :

$$
\delta_{x}=\frac{C_{d} \delta_{x e}}{I}
$$

(Rumus 3.1)

Dimana :

$\delta \mathrm{e} \quad=$ Defleksi pada lantai ke- $\mathrm{x}$

$C_{d}=$ Faktor pembesaran defleksi $(5,5)$

$I \quad=$ Faktor keutamaan gempa

IV. HASIL PERENCANAAN STRUKTUR

\section{A. Data Perencanaan}

Data bangunan yang akan digunakan dalam pengerjaan Studi yaitu :

- Tipe bangunan : Hotel

- Ketinggian lantai : $3,5 \mathrm{~m}$

- Tinggi bangunan : $59,5 \mathrm{~m}$

- Mutu beton (fc)

$\begin{array}{ll}\text { Balok } & : 30 \mathrm{Mpa} \\ \text { Kolom } & : 35 \mathrm{Mpa} \\ \text { Mutu baja (fy) } & : 400 \mathrm{Mpa}\end{array}$

Tabel 5 .

\begin{tabular}{|c|c|c|c|c|c|c|c|}
\hline $\begin{array}{c}\text { Lant } \\
\text { ai }\end{array}$ & $\begin{array}{c}\text { Elev } \\
\text { asi }\end{array}$ & $\begin{array}{l}\text { Ting } \\
\text { gi } \\
\text { Lant } \\
\text { ai }\end{array}$ & $\begin{array}{c}\text { Simpan } \\
\text { gan }\end{array}$ & $\begin{array}{c}\text { Simpan } \\
\text { gan } \\
\text { Diperbe } \\
\text { sar }\end{array}$ & $\begin{array}{c}\text { Simpan } \\
\text { gan } \\
\text { Antar } \\
\text { Lantai }\end{array}$ & $\begin{array}{c}\text { Simpan } \\
\text { gan Ijin } \\
\text { Antar } \\
\text { Lantai }\end{array}$ & $\begin{array}{c}\mathrm{KE} \\
\mathrm{T} .\end{array}$ \\
\hline I & $\begin{array}{c}\text { (m) } \\
\mathrm{hi}\end{array}$ & $\begin{array}{c}\text { (m) } \\
\text { hsx } \\
\text { hi-(hi- } \\
\text { 1) }\end{array}$ & $\underset{\delta \mathrm{e}}{(\mathrm{mm})}$ & $\begin{array}{c}(\mathrm{mm}) \\
\delta \\
\delta \mathrm{e} \cdot \mathrm{Cd} / \mathrm{Ie}\end{array}$ & $\begin{array}{c}(\mathrm{mm}) \\
\Delta \\
\delta \mathrm{i}-\delta(\mathrm{i}-1)\end{array}$ & $\begin{array}{c}(\mathrm{mm}) \\
\Delta \mathrm{a} \\
0,02 \cdot \mathrm{hsx}\end{array}$ & \\
\hline $\begin{array}{l}\text { Lantai } \\
\text { BS 2 }\end{array}$ & -6 & 0 & 0.000 & 0.000 & 0.000 & 0 & OK \\
\hline $\begin{array}{l}\text { Lantai } \\
\text { BS } 1\end{array}$ & -3 & 3 & 0.029 & 0.160 & 0.160 & 60 & $\mathrm{OK}$ \\
\hline $\begin{array}{l}\text { Lantai } \\
\text { Dasar }\end{array}$ & 0 & 3 & 0.117 & 0.644 & 0.484 & 60 & OK \\
\hline $\begin{array}{l}\text { Lantai } \\
2\end{array}$ & 3.5 & 3.5 & 2.108 & 11.594 & 10.951 & 70 & OK \\
\hline $\begin{array}{l}\text { Lantai } \\
3\end{array}$ & 7 & 3.5 & 5.621 & 30.916 & 19.322 & 70 & OK \\
\hline $\begin{array}{l}\text { Lantai } \\
4\end{array}$ & 10.5 & 3.5 & 9.987 & 54.929 & 24.013 & 70 & $\mathrm{OK}$ \\
\hline $\begin{array}{l}\text { Lantai } \\
5\end{array}$ & 14 & 3.5 & 14.660 & 80.630 & 25.702 & 70 & $\mathrm{OK}$ \\
\hline $\begin{array}{l}\text { Lantai } \\
6\end{array}$ & 17.5 & 3.5 & 19.343 & 106.387 & 25.757 & 70 & $\mathrm{OK}$ \\
\hline $\begin{array}{l}\text { Lantai } \\
7\end{array}$ & 21 & 3.5 & 23.899 & 131.445 & 25.058 & 70 & OK \\
\hline $\begin{array}{l}\text { Lantai } \\
8\end{array}$ & 24.5 & 3.5 & 28.269 & 155.480 & 24.035 & 70 & OK \\
\hline $\begin{array}{l}\text { Lantai } \\
9\end{array}$ & 28 & 3.5 & 32.549 & 179.020 & 23.540 & 70 & OK \\
\hline $\begin{array}{l}\text { Lantai } \\
10\end{array}$ & 31.5 & 3.5 & 36.522 & 200.871 & 21.852 & 70 & $\mathrm{OK}$ \\
\hline $\begin{array}{l}\text { Lantai } \\
11\end{array}$ & 35 & 3.5 & 40.175 & 220.963 & 20.092 & 70 & OK \\
\hline $\begin{array}{l}\text { Lantai } \\
12\end{array}$ & 38.5 & 3.5 & 43.491 & 239.201 & 18.238 & 70 & $\mathrm{OK}$ \\
\hline $\begin{array}{l}\text { Lantai } \\
13\end{array}$ & 42 & 3.5 & 46.463 & 255.547 & 16.346 & 70 & $\mathrm{OK}$ \\
\hline $\begin{array}{l}\text { Lantai } \\
14\end{array}$ & 45.5 & 3.5 & 49.181 & 270.496 & 14.949 & 70 & $\mathrm{OK}$ \\
\hline $\begin{array}{l}\text { Lantai } \\
15\end{array}$ & 49 & 3.5 & 51.416 & 282.788 & 12.293 & 70 & OK \\
\hline $\begin{array}{l}\text { Lantai } \\
16\end{array}$ & 52.5 & 3.5 & 53.245 & 292.848 & 10.060 & 70 & $\mathrm{OK}$ \\
\hline $\begin{array}{l}\text { Lantai } \\
17\end{array}$ & 56 & 3.5 & 54.651 & 300.581 & 7.733 & 70 & $\mathrm{OK}$ \\
\hline $\begin{array}{l}\text { Lantai } \\
18\end{array}$ & 59.5 & 3.5 & 54.446 & 299.453 & 1.128 & 70 & $\mathrm{OK}$ \\
\hline
\end{tabular}

Kontrol Simpangan

\section{B. Preliminary Design}

1. Balok

Hasil dari Preliminary Design struktur balok dapat dilihat pada table 6 .

Tabel 6.

Dimensi Balok

\begin{tabular}{lccc}
\hline \hline & \multicolumn{3}{c}{ Dimensi $(\mathrm{cm})$} \\
& $\begin{array}{c}\text { Bentang } \\
(\mathrm{m})\end{array}$ & $\mathrm{b}$ & $\mathrm{h}$ \\
\hline B1 (Primer) & 7 & 45 & 60 \\
B2 (Primer) & 7,55 & 45 & 60 \\
BA1 (Sekunder) & 7.55 & 30 & 40 \\
BP1 (Prategang) & 12,25 & 45 & 65 \\
\hline \hline
\end{tabular}

2. Balok Prategang

Balok Prategang yang direcanakan memiliki $\mathrm{L}=$ $12,25 \mathrm{~m}$, sehingga diperoleh perencanaan $45 / 65$ untuk balok prategang

3. Plat
- Lantai dan atap
$: 12 \mathrm{~cm}$
- Basement
$: 25 \mathrm{~cm}$

4. Tangga 
Syarat Perencanaan :

$60 \leq 2 . t+i \leq 65$

Lebar injakan (i) diambil $: 25 \mathrm{~cm}$

Tinggi injakan (t) diambil : $18 \mathrm{~cm}$

$60 \leq 2.18+27 \leq 65$

$61 \leq 63 \leq 65 \quad($ OKE)

- Mutu Beton (f'c) : $30 \mathrm{Mpa}$

- Mutu Baja (fy) : $400 \mathrm{Mpa}$

- Panjang Bordes $\quad: 274 \mathrm{~cm}$

- Lebar Bordes $\quad: 100 \mathrm{~cm}$

- Lebar Tangga $\quad: 137 \mathrm{~cm}$

- Tebal Pelat miring $\quad: 15 \mathrm{~cm}$

- Tebal Pelat Bordes : $15 \mathrm{~cm}$

- Tebal Selimut Beton : $20 \mathrm{~cm}$

- Tinggi injakan (t) $: 18 \mathrm{~cm}$

- Lebar Injakan (i) $\quad: 27 \mathrm{~cm}$

- Jumlah tanjakan (n) $\frac{\text { tinggi lantai }}{t}=10$ buah

- Jumlah injakan (n-1) : 9

- Kemiringan tangga $(\alpha): \operatorname{arc} \operatorname{tg}(18 / 27)=34^{\circ}$

- Syarat sudut kemiringan

$$
\begin{aligned}
& 25^{0} \leq \alpha \leq 40^{0} \\
& 25^{0} \leq 34^{0} \leq 40^{0} \rightarrow \text { Memenuhi }
\end{aligned}
$$

5. Balok Lift

Balok Penumpu lift

- Tipe lift

- Merek

: Passenger Elevators

- Kapasitas

: Hyundai

- Lebar pintu (opening width) : $900 \mathrm{~mm}$

- Dimensi ruang luncur

(hoistway inside) 2 Car: 4200 × $2100 \mathrm{~mm}^{2}$

- Dimensi sangkar (Car size)

Internal

Eksternal

: $1600 \times 1500 \mathrm{~mm}^{2}$

: $1660 \times 1665 \mathrm{~mm}^{2}$

- Ruang mesin(2 Car): 4400 x $3850 \mathrm{~mm}^{2}$

- Beban reaksi ruang mesin:

$$
\mathrm{R}_{1}: 5450 \mathrm{~kg}
$$

$\mathrm{R}_{2}: 4350 \mathrm{~kg}$

- Penumpu Balok 30/40 cm

6. Kolom

Tabel 7.

Dimensi Kolom

\begin{tabular}{lcc}
\hline \multicolumn{1}{c}{ Tipe Kolom } & \multicolumn{2}{c}{ Dimensi } \\
& $\begin{array}{c}\text { b } \\
\mathrm{cm}\end{array}$ & $\mathrm{c}$ \\
& $\mathrm{cm}$ \\
\hline K4 (Lt. 13 - 17) & 70 & 70 \\
K3 (Lt. 8 - 12) & 80 & 80 \\
K2 (Lt. 3 - 7) & 90 & 90 \\
K1 (Lt. Basement - 2) & 100 & 100 \\
\hline \hline
\end{tabular}

C. Perencanaan Struktur Sekunder

1. Penulangan Pelat Lantai

$\mathrm{Fc} \quad=30 \mathrm{Mpa}$

Fy $\quad=400 \mathrm{Mpa}$

Digunakan tulangan lentur arah X D10-200

Dibunakan tulangan lentur arah Y D10-200

2. Desain Balok Anak

Data Perencanaan :

Fc $\quad=30 \mathrm{Mpa}$

Fy $\quad=400 \mathrm{Mpa}$

Digunakan tulangan lentur tumpuan 3D16

Digunakan tulangan geser tumpuan 2D10-150

Digunakan tulangan lentur lapangan 3D16

Digunakan tulangan geser lapangan 2D10-170

3. Desain Tangga

a. Penulangaan pelat tangga $\begin{aligned} \mathrm{Fc} & =30 \mathrm{Mpa} \\ \mathrm{Fy} & =400 \mathrm{Mpa}\end{aligned}$

Digunakan tulangan lentur arah X D13-150

Dibunakan tulangan lentur arah Y D13-150

b. Penulangan pelat bordes

$\mathrm{Fc} \quad=30 \mathrm{Mpa}$

Fy $=400 \mathrm{Mpa}$

Digunakan tulangan lentur arah X D13-200

Dibunakan tulangan lentur arah Y D13-200

4. Desain Balok Lift

Data Perencanaan :

$\mathrm{Fc} \quad=30 \mathrm{Mpa}$

Fy $\quad=400 \mathrm{Mpa}$

Digunakan tulangan lentur tumpuan 5D19

Digunakan tulangan geser tumpuan 2D13-125

Digunakan tulangan lentur lapangan 3D19

Digunakan tulangan geser lapangan 2D13-150

D. Perencanaan Struktur Balok Prategang

- Dimensi Balok : :45/65 mm

- Bentang Balok : $12250 \mathrm{~mm}$

- Mutu Beton $\left(f c^{\prime}\right) \quad$ : $50 \mathrm{Mpa}$

- Mutu Tendon

- Menggunakan data dari tabel prestresssing strand - 7 wire, uncoated ASTM A416 untuk post tensioning

- Nominal diameter $\quad: 12,7 \mathrm{~mm}$

- Luas nominal area kawat: $100,1 \mathrm{~mm}^{2}$

- Minimal breaking load : $184 \mathrm{kN}$

Detail penulangan Balok Prategang:

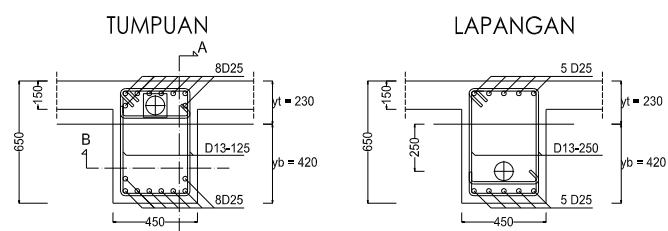

Gambar 4.1 Rencana penulangan balok prategang

$$
\begin{gathered}
P P R=\frac{M_{n p}}{M_{n}}=\frac{1670,42}{2218,47}=75,3 \% \leq 80 \%(O K) \\
\phi M_{n}=0,9 \times 2218,47 \\
1996,62 \mathrm{kNm}>1,2 M_{c r}
\end{gathered}
$$

Kehilangan ptrategang :

Tabel 8.

Rekapitulasi Perhitungan kehilangan tegangan \begin{tabular}{llll}
\hline Level tegangan pada berbagai tahap & Tegangan baja, $M P a$ & Persen \\
\hline
\end{tabular}

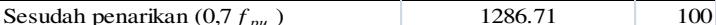
\begin{tabular}{|l|l|l|}
\hline Kehilangan akibat perpendekan elastis & 0 & 0.00 \\
\hline
\end{tabular} Kehilangan akibat angker

Kehilangan akibat wobble effect

Kehilangan akibat kekangan kolom

Kehilangan akibat rangkak

Kehilangan akibat susut

Kehilangan akibat relaksasi baja

Pertambahan karena topping

Tegangan netto akhir fpe

Persentase kehilangan total $=$

Kontrol Lendutan :

Lendutan ijin : $\Delta_{i j i n}=\frac{L}{480}=\frac{12250}{480}=25,5 \mathrm{~mm}$

Lendutan total :

$$
\begin{aligned}
\Delta l_{A} & =\Delta l_{P O}+\Delta l_{q O}+\Delta l_{m e} \\
& =-15,81+11,6+7,59=3,38 \mathrm{~mm}(\downarrow)<25,5 \mathrm{~mm} \\
& =3,38 \mathrm{~mm}<25,5 \mathrm{~mm} \ldots \ldots \ldots \ldots \ldots .(\text { Oke })
\end{aligned}
$$

Keterangan : 
$\Delta l_{P O}=$ Lendutan Akibat Tekanan Tendon

$\Delta l_{q O}=$ Lendutan Akibat Beban kerja

$\Delta l_{m e}=$ Lendutan Akibat Eksentrisitas

E. Perencanaan Struktur Primer

1. Perencanaan balok induk B2

: 45/60 $\mathrm{mm}$

- Bentang Balok

: $7550 \mathrm{~mm}$

- Selimut Beton

$: 40 \mathrm{~mm}$

- Dia. Tul. Utama (D)

: $22 \mathrm{~mm}$

- Dia. Tul. Sengkang (D)

: $13 \mathrm{~mm}$
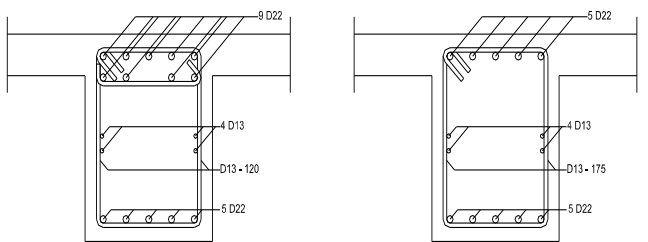

Gambar 4.2 Rencana Penulangan Balok Induk (B2)

2. Perencanaan kolom $\mathrm{K} 1$

- Tinggi kolom

$: 3,5 \mathrm{~m}$

- Dimensi kolom

: $900 \times 900 \mathrm{~mm}$

- Tul. Memanjang (D)

: $24 \mathrm{D} 25 \mathrm{~mm}$

- Tul. Sengkang (D)

Detail penulangan kolom
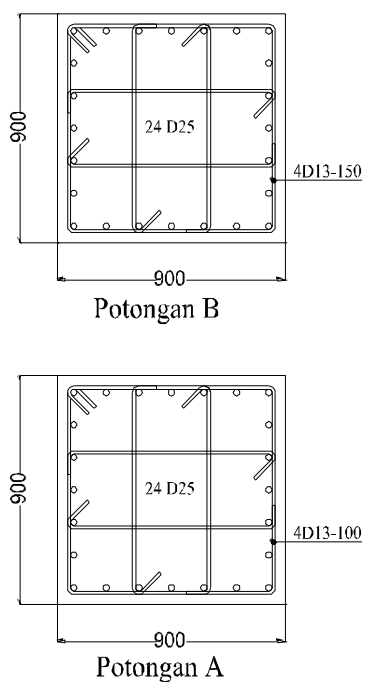

Gambar 4.3 Rencana Penulangan Kolom Tipe K1

\section{F. Perencanaan Struktur Bawah}

1. Daya Dukung Tiang Berdasarkan Bahan

- Diameter tiang : $600 \mathrm{~mm}$

- Klasifikasi : A1

- Modulus Section $\quad: 17255,62 \mathrm{~cm}^{3}$

- Allowable axial load : 252,7 ton

- Bending Momen Crack : 17 tm

- Bending momen ulltimate : 25,5 tm

2. Daya Dukung Tiang Berdasarkan Tanah

Perhitungan daya dukung tiang pancang ini dilakukan berdasarkan hasil uji Standard Penetration Test (SPT) dengan kedalaman $21 \mathrm{~m}$ menggunakan metode Mayerhoff :

$P_{i j \text { in 1 tiang }}=\frac{Q u}{S F}=\frac{693,01}{3}=231$ ton

Daya dukung tanah yang menentukan yaitu 231 ton
3. Perencanaan Pondasi Tipe PC1

Direncanakan pondasi tiang dengan 6 tiang pancang. Jarak dari as ke as tiang adalah 1,5 meter dan tebal pile cap 1,2 m. Berikut hasil perencanaan pondasi:
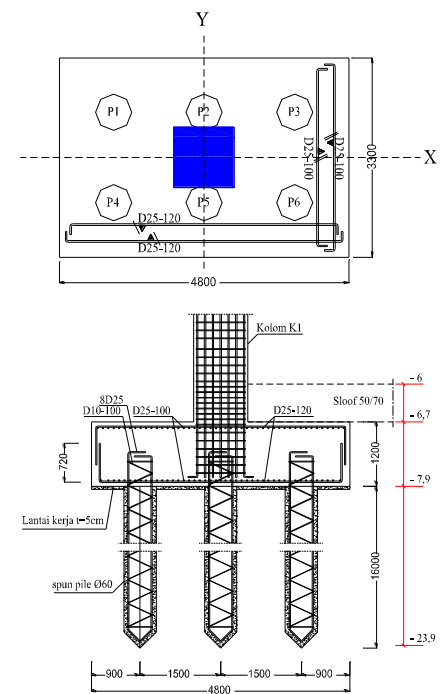

Gambar 4.4 Penulangan Tiang Pancang Tipe PC 1

V.

PENUTUP

Dari perhitungan-perhitungan yang telah dijelaskan pada bab sebelumnya didapatkan kesimpulan sesuai tujuan penulisan Studi "Desain Modifikasi Struktur Gedung Hotel Premier Inn Surabaya dengan Menggunakan Beton Prategang dan Sistem Rangka Pemikul Momen Khusus" dengan gambar teknis pada lampiran dan hasil analisa sebagai berikut :

1. Perencanaan Gedung Hotel Premier Inn Surabaya pada zona gempa tinggi, memiliki dimensi - dimensi struktur baik struktur sekunder maupun struktur primer sebagai berikut :

Struktur Sekunder :

- Balok anak : :30/40 cm

- Balok lift $\quad: 30 / 40 \mathrm{~cm}$

- Tebal plat $\quad: 12 \mathrm{~cm}$

Struktur Utama :

- Balok Prategang : :45/65 cm

- Balok Induk : :45/60 cm

- Kolom K1 : :100/100 cm

- Kolom K2 : :90/90 cm

- Kolom K3 : :80/80 cm

- Kolom K4 : :70/70 cm

- Tiang pancang : D-60, $\mathrm{H}=16 \mathrm{~m}$

2. Dari hasil analisis beban gempa, struktur gedung termasuk ke dalam kategori desain seismik D dengan demikian konfigurasi yang diterapakan adalah SRPMK. Berdasarkan program analisis struktur didapatkan kontrol waktu getar alami (T) sebesar 2,228 detik < $\mathrm{Cu}$. Ta $=2,81$ detik, kontrol partisipasi massa memenuhi syarat yaitu pada mode 20 , kontrol nilai akhir respon spektrum (V) dinamik arah x dan y sebesar 468518,698 $\mathrm{kg}$, dan memenuhi kontrol drift (simpangan) yaitu tidak boleh melebihi $60 \mathrm{~mm}$.

3. Balok prategang direncanakan dengan sistem pascatarik dengan satu buah tendon yang didongkrak secara simultan sekaligus sehingga kehilangan tegangan akibat perpendekan elastis tidak terjadi. Berdasarkan 
perhitungan, kehilangan tegangan secara langsung dan tidak langsung yang terjadi pada balok prategang yaitu sebesar $21,14 \%$

4. Kehilangan prategang akibat kekangan kolom harus diperhitungkan untuk balok prategang yang dipasang dengan cara cor ditempat menyatu dengan kolom. Hal ini dikarenakan gaya jacking ditahan sebagian oleh kolom dan akan menghasilkan momen tambahan pada kolom sebesar kehilangan tegangan pada balok prategang.

5. Penggunaan beton prategang pada gedung bertingkat perlu diperhatikan kemampuan dalam menerima beban gempa yang terjadi pada struktur. Untuk membuat balok prategang dapat menerima beban gempa maka balok prategang didesain berperilaku daktail dengan memberikan baja lunak dengan perbandingan PPR sebesar 75,3\%. Baja lunak ditujukan untuk mendisipasikan energi gempa dengan cara meleleh. Baja prategang memberikan ketahanan geser dari friksi yang ditimbulkan gaya prategang.

\section{DAFTAR PUSTAKA}

[1] E. G. Nawy, Prestressed Concrete : A Fundamental Approach, Terjemahan. Jakarta: Erlangga, 1996.

[2] I. G. P. Raka, Tavio, and M. D. Astawa., "State-of-the-Art Report on Partially-Prestressed Concrete Earthquake- Resistant Building Structures for Highly-Seismic Region," in Procedia Engineering, 2014, pp. 43-53.

[3] T. Y. Lin and N. H. Burn, Desain Struktur Beton Prategang Edisi Ketiga Jilid 1, Terjemahan. Jakarta: Binarupa Aksara, 2000. 